\title{
ELS SARRAIINS DEL REGNE DE MÚRCIA DURANT LA CONQUESTA DE JAUME II (1296-1304)
}

\author{
Maria Teresa FERRER I MALLOL \\ Institució Milà i Fontanals. CSIC
}

Amb la conquesta del regne de Múrcia per Jaume II durant la guerra contra Castella de 1296-1304, la Corona catalano-aragonesa incorporava un altre regne amb una proporció molt important de població sarraïna. Com al regne de València, una gran part de la població auctòctona de religió islàmica havia romàs al regne, tant a conseqüència del protectorat de Castella acordat a Alcaraz, el 1243, com per les capitulacions pactades amb Jaume I quan aquest monarca conquerí el regne després de la sublevació del 1264'. Malgrat que les primeres operacions militars castellanes de mitjan segle XIII i la conquesta de Jaume I havien provocat l'emigració d'un nombre molt considerable de sarraïns murcians, eren encara una minoria important, bé que en regressió.

Sembla que els castellans no posaven gaires obstacles a l'emigració dels sarraïns cap a Granada; el fet que els deixessin vendre els seus béns a cristians facilitava la marxa del sector més benestant ${ }^{2}$; altrament, algunes mesures preses a Castella contra els sarraïns degueren accentuar la incomoditat que sentien sota domini cristià $i$ potser n'estimularen l'emigració. Em refereixo concretament a dues qüestions posades en evidència pel Prof. Torres-Fontes: en primer lloc, les restriccions imposades a la pràctica religiosa ja durant el regnat d'Alfons el Savi, concretament la prohibició de la crida de la salà, és a dir, la crida a l'oració que feia el muetzí des dels minarets de les mesquites $^{3}$; era una manifestació religiosa amb la qual la població islàmica se sentia

Cf. sobre aquest tema l'excel.lent treball del Prof. J. TORRES FONTES, La reconquista de Murcia en 1266 por Jaime I de Aragón, Murcia, Patronato de Cultura de la Excma. Diputación Provincial de Murcia, 1967.

2 J. TORRES FONTES, "Los mudéjares murcianos en el siglo XIIl», Murgetana, XVII (1961) p. 9.

3 Ibidem, p. 21. 
molt identificada, però que desvetllava una hostilitat manifesta en la Església, que s'esforçà a fer-la prohibir en terres cristianes, cosa que no aconseguí a la Corona catalano-aragonesa fins el $1318^{4}$. Per les reaccions que aquesta prohibició suscità entre els sarraïns d'aquest darrer estat, podem suposar el malcontentament que degué provocar a Castella. En segon lloc, la prohibició de tenir propietats, decidida a les Corts de Valladolid del $1293^{5}$, degué suposar un altre cop molt dur per a la població islàmica sotmesa a Castella i potser influí, com diu Guichard, en l'actitud favorable a Jaume II que la comunitat musulmana adoptà arran de la invasió del regne de Múrcia ${ }^{6}$.

Veurem ara on s'assentava la població islàmica en aquest territori. A la part septentrional del regne, la població cristiana es concentrava a la plana litoral, mentre que la vall del Vinalopó era majoritàriament de població sarraïna: comprenia la moreria urbana i l'horta d'Elx, Crevillent, Elda, Novelda, Petrer, Xinosa, Monòver i Asp. Fora d'aquest nucli més compacte, l'horta d'Oriola també comptava amb un nombre considerable d'habitants sarraïns i la vila tenia una moreria urbana, bé que força més reduïda que la d'Elx; a l'horta d'Alacant i a la moreria d'aquesta vila hi vivien, igualment, petites comunitats sarrainnes.

A la part meridional del regne -l'actual província de Múrcia - el litoral era molt despoblat; l'únic nucli destacable, malgrat que era de dimensions reduïdes, era Cartagena, amb una petita moreria. La població cristiana es concentrava a la ciutat de Múrcia i a les viles de Lorca i Mula, mentre que els sarraïns predominaven a la vall de Ricote, a l'horta i al camp de Múrcia i a la mateixa capital, que comptava amb una moreria important; cal esmentar també un petit nucli sarraí a Mula ${ }^{7}$, mentre que no he trobat cap notícia relativa a Lorca. La vall de Ricote comprenia diversos nuclis habitats: Ricote, Blanca, Abarán, Ulea, Ojós, Asuete o Villanueva. A l'horta i camp de Múrcia, sabem que comptaven amb població sarraïna Lorquí, Ceutí, Molina, Alguazas — conegudes a la documentació catalana com les Alguastes- Pliego i Albudeite, Alcantarilla, Cotillas etc., a més de Favanella —Abanilla en castellà-, que els primers temps quedà lligada a la Corona catalano-aragonesa, i Fortuna ${ }^{8}$, que eren els nuclis més pròxims a la frontera quan el regne es dividí.

4 M.T. FERRER I MALLOL, Els sarrains de la Corona catalano-aragonesa en el segle XIV. Segregació I discriminació, Barcelona, CSIC. Institució Milà i Fontanals, 1987, pp. 88-95.

5 J. TORRES FONTES, Los mudéjares murcianos en el siglo XIII, pp. 24-25.

6 P. GUICHARD, Un señor musulmán en la España cristiana: el «ra'is de Crevillente (1243-1318), Alacant, 1976, pp. 26-27.

7 Sembla que en altre temps Mula havia tingut una moreria important: J. TORRES FONTES, Los mudéjares murcianos en el siglo XIII, pp. 26-27.

8 Sobre el lloc de Fortuna cf. J. TORRES FONTES, «Fortuna en los siglos XIII y XIV», Murgetana, XXVIII (1968), pp. 47-102.

9 Cf. les panoràmiques generals dels moros murcians durant la baixa Edat Mitjana traçades per J. TORRES FONTES, "Los mudéjares murcianos en la Edad Media", III Simposio Internacional de Mudejarismo (Teruel, 1984). Actas, Terol, Instituto de Estudios Turolenses, 1986, pp. 55-66, i a «Los mudéjares murcianos: economía y sociedad", a IV Simposio Internacional de Mudejarismo: Economía (Teruel, 1987), Terol, Instituto de Estudios Turolenses, 1992, pp. 365-393, així com «Murcia Medieval. Testimonio documental. VIII. Los mudéjares», Murgetana, 59 (1980), pp. 115-158. També A. L. MOLINA 
M'ocuparé només dels sarraïns durant els anys de la guerra. M'ha semblat que així el meu treball serà més homogeni perquè, altrament, tindria molta documentació per a la part septentrional de l'antic regne i poca, o no gens original, per a la part meridional. Aquesta decisió farà que em limiti, especialment, als efectes de la guerra sobre les diverses comunitats sarraïnes.

\section{LA GUERRA, CAUSA DE DESPOBLACIÓ}

La guerra de 1296-1304, com totes les guerres, afectà la minoria sarraïna i provocà un descens demogràfic. Alguns sarraïns degueren morir en les operacions bèl.liques, uns altres foren capturats $i$, en virtut del principi pel qual tot sarraí suposadament rebel quedava reduït a captivitat, foren venuts i portats sovint lluny de les seves terres; d'altres sarraïns emigraren cap al regne de València, fora de l'àrea de guerra ${ }^{10}$, i altres, si els fou possible, fugiren a Granada. Cal tenir en compte que les guerres eren sempre d'efectes més desastrosos per a les minories, sarraïns i jueus, que no pas per als cristians, perquè eren les víctimes preferides dels excessos dels soldats.

Acabada la guerra, una carta de Ferran IV dóna testimoni d'aquesta minva de la població sarraïna a la part del regne de Múrcia que tornà a mans de Castella: «por razón de las guerras e de los otros males que son acaescidos en tierra de Murcia, la mayor parte de los moros son muertos e los otros fuydos, por las quales cosas la tierra es muy despoblada e menguada dellos" "1.

L'inici de les operacions bèl-liques provocà una desbandada entre els sarraïns, principalment entre els que vivien a les zones rurals, per a refugiar-se a indrets considerats més segurs. Els primers afectats foren els moros d'Alacant; ni els que vivien a la rodalia ni els que vivien al raval de la vila no podien comptar amb la protecció de les muralles de la ciutat, on en temps de guerra la presència dels sarraïns no era gaire apreciada per la manca de confiança en la seva lleialtat.

Fora dels murs protectors, els esperaven tota mena de desgràcies: la mort, la captura i la reducció a la servitud. Un exèrcit en campanya era sempre perillós, oimés per als sarraïns, que eren ciutadans de segona. Els sarraïns d'Alacant, doncs, anaren a refugiar-se a Crevillent, el darrer senyoriu que s'havia mantingut en mans d'un noble musulmà, l'arrais de Crevillent, de qui esperaven protecció; ell podia negociar amb el rei i ja es devia saber que havia estat visitat pels emissaris de Jaume $\|^{12}$.

MOLINA, La vida en Murcia a finales de la Edad media, Academia Alfonso X el Sabio, discurso de recepción, Múrcia, 1983, i “Los mudéjares en el reino de Murcia», Áreas, 14 (1992), pp. 91-106.

10 És el cas, per exemple, d'Ahayan Huarat Façon, que marxà a viure a València amb la mare, la germana, la muller i un fill des de Crevillent, on residia: ACA, C, reg. 198 v. (1296, juliol, 6).

11 J. TORRES FONTES, Los mudéjares murcianos, p. 27.

12 P. GUICHARD, Un señor musulmán en la España cristiana, p. 22; J.M. del ESTAL, "Vasallaje del señorío musulmán de Crevillente a Jaime II de Aragón», Sharq Al-Andalus. Estudios Árabes, 2 (1985), doc. V; M.T. FERRER I MALLOL, Les aljames sarraïnes de la governació d'Oriola en el segle XIV, Barcelona, Institució Milà i Fontanals, 1988, p. 16 i doc. 1, i J.M. del ESTAL, El reino de Murcia bajo Aragón (1296-1305). Corpus documental, I/2, Alacant, Instituto de Cultura «Juan Gil-Albert», Di- 
Molts més sarraïns, com també els cristians, abandonaren les cases i degueren amagar-se a les muntanyes, fugint dels almogàvers i de la gent de guerra, o bé marxaren a Elx, que essent senyoriu de don Juan Manuel, de la família reial castellana, els devia semblar més segur, $\mathrm{o}$ als dominis dels ordes militars. Després tornaren als llocs ocupats per Jaume II, des que hi hagué ordre. El mes de maig de 1296, quan ja es devia veure pròxim l'atac a Elx, moros d'aquesta vila fugiren cap a Alacant, que ja era en poder de Jaume II i on no calia témer cap episodi bèl.lic ${ }^{13}$.

$\mathrm{Hi}$ ha nombrosos testimonis de captures de sarraïns; si havien estat fetes violant guiatges atorgats pel rei i algú amb influència s'encarregà de reclamar-los, els afectats aconseguiren la llibertat. És el cas de dos sarraïns innominats presos per Ato de Lisón i que pel juny de 1296 eren en poder de Bernat Pujades, alcaid del castell de Callosa. L'arrais de Crevillent els reclamà a Jaume $\mathrm{II} \mathrm{i}$ el rei ordenà que fossin retornats ${ }^{14}$. Pel maig, una cavalcada pel terme d'Albudeite produí almenys 80 sarraïns captius i que Jaume II autoritzà que fossin venuts perquè, quan foren presos, aquest lloc estava en guerra amb ell15. Dels sarrains portats a Oriola per l'adalil Vicenç de Xixona, que havien estat presos en una cavalcada per Ceutí, Lorquí i les Alguazas, els capturats en aquest darrer lloc hagueren de ser alliberats perque el rei no volia causar perjudicis al seu conseller Ramon de Manresa, a qui havia donat el $l \operatorname{loc}^{16}$. Hi ha constància, en canvi, que els procedents de Lorquí foren venuts ${ }^{17}$; la licitud de la captura d'algun altre presoner, pres igualment per Vicenç de Xixona, fou objecte d'una llarga controvèrsia perquè en el moment de la captura no es veia prou clar si ja era vigent el guiatge atorgat pel rei als sarraïns d'Asp ${ }^{18}$. També Ferran Garcés de Rueda reclamà per la captura de quatre sarraïns de l'alqueria de Catral, al terme d'Oriola, que el rei li havia donat. A la darreria de juliol, n'havia recuperats dos ${ }^{19}$.

Alguns membres de l'exèrcit enviaren els captius aconseguits cap al seu lloc

putación de Alicante, 1990, l/2, doc. 18. Pel que fa als emissaris enviats a l'arrais, abans de la invasió, cf. M.T. FERRER I MALLOL, Notes sobre la conquesta del regne de Múrcia per Jaume 1/ (1296-1304), a Homenatge a la memòria del Prof. Dr. Emilio Sáez. Aplec d'estudis dels seus deixebles i col.laboradors, Barcelona, Universitat de Barcelona, Centre d'Estudis Medievals de Catalunya i Institució Milà i Fontanals, 1989 , p. 30.

13 A. GIMÉNEZ SOLER, Don Juan Manuel. Biografía y estudio crítico, Saragossa, 1932, doc. 63. M. del ESTAL, Vasallaje del señorío musulmán de Crevillente a Jaime Il de Aragón, doc. II; M.T. FERRER I MALLOL, Les aljames sarraïnes, pp. 50-51 i doc. 3, 15 i 16; J. M. del ESTAL, El reino de Murcia bajo Aragón, $1 / 2$, doc. 23.

14 ACA, C, reg. 340 , f. 130 v. (1296, juny, 13).

15 ACA, C, reg. 340, f. 85 v. (1296, maig, 22).

16 ACA, C, reg. 340, f. 71 r. (1296, maig, 17), publ. per J. M. del ESTAL, El reino de Murcia bajo la soberanía de Aragón (1296-1304/1305). Corpus documental, Alacant, Instituto de Estudios Juan Gil Albert, 1985, 1/1, doc. 64.

17 Ibidem, f. 73 r. i v. (1296, maig, 17 i 18).

18 ACA, C, reg. 340, f. 201 v (1296, juliol, 7) i reg. 104, f. 29 r.-v., 36 r., 55 r. (1296, agost, 11, 16, 21). Cit. el primer per P. GUICHARD, Un señor musulmán en la España cristiana, p. 27.

19 M.T. FERRER I MALLOL, La frontera amb l'slam en el segle XIV. Cristians i sarraïns al País Valencià, Barcelona, Institució Milà i Fontanals. CSIC, 1988, doc. 6. 
d'origen, com Gil de Jaca, que envià una nena sarraïna de sis anys cap a Aragó amb el seu escuder Joan Ferrer ${ }^{20}$. Altres, com Pere de Montagut de Carlet, foren autoritzats a vendre els captius aconseguits, considerats de bona guerra, en aquest cas dues sarraïnes, Nussa i Çofra, i un sarraï, Mafumet ${ }^{21}$. Sabem que molts dels sarraïns capturats foren retinguts a Oriola, a Guardamar i a Alacant, d'on alguns intentaren fugir ${ }^{22}$. A vegades, alguns sarraïns foren tan desgraciats que, havent estat capturats pels castellans i portats a una de les viles que resistiren, la seva situació resultà consolidada per ignorància quan la vila fou presa per Jaume Il. És el que li esdevingué a Façén, un moro de la Reixaca de Múrcia, que pel gener de 1301 encara era presoner a Lorca perquè un clergue del Iloc, callant el seu origen, havia sol-licitat a Jaume II que I'hi donés. Només quan el pare de Façén, Mahomet, es presentà al rei, que es trobava llavors a Múrcia i, plorant, li explicà el cas del seu fill, el monarca ordenà desfer aquest greuge tan $\operatorname{gros}^{23}$.

Una de les primeres preocupacions de govern de Jaume II, a mesura que anava adquirint territori del regne, fou la de tranquil.litzar els camperols sarraïns, que posà sota el seu guiatge perquè tornessin a les seves cases i reprenguessin les tasques agrícoles. Com que la intervenció de l'arrais de Crevillent els donava més confiança, Jaume II autoritzà aquest personatge a assegurar tots els sarraïns del regne de Múrcia $i$ els seus béns o a donar-los guiatge en nom seu, a fi que tornessin a llurs cases, mentre el reconeguessin com a senyor i rei de Múrcia, tot declarant que els tractaria bé, com ho havien fet els seus predecessors. A precs de l'arrais, el monarca autoritzà també els captius sarraïns que s'havien refugiat a Crevillent a romandre-hi segurs ${ }^{24}$.

Quan el regne estigué pràcticament tot sota control de Jaume II, foren les incursions castellanes les que causaren danys i espant als sarrains i possiblement captius. Una incursió castellana de cap al març de 1303 aterri els sarraïns de l'horta d'Elx que, segons el rei, eren «fort esmayats», fins a tal punt que en volien marxar. Per tal d'evitarho, el rei demanà a l'arrais de Crevillent que es reunís amb els vells i l'aljama de moros d'Elx i els calmés, prometent-los la tramesa de tropes per a protegir-los i un tracte menys rigorós pel que feia a exaccions reials i peites, a fi que no es moguessin. Assegurava que des de llavors els privilegis els serien observats i no serien «leig menats» ${ }^{25}$.

L'atac sofert havia coincidit amb l'absència, a més, dels moros joves o més preparats per a la guerra que, per ordre de Bernat de Sarrià, participaven en el setge de Mula.

20 Jaume II ordenà als seus oficials que els deixessin passar: ACA, C, reg. 340, f. 154 v. (1296, juny, 18).

21 ACA, C, reg. 105, f. 122 r. (1296, setembre, 24).

$22 \mathrm{ACA}, \mathrm{C}$, reg. 340, ff. $144 \mathrm{r}$. i $149 \mathrm{v}$. Els guardats a Oriola i Guardamar procedien d'Elx i Crevillent.

23 ACA, C, reg. 118, ff. 6 v.-7 r. (1301, gener, 16).

24 P. GUICHARD, Un señor musulmán en la España cristiana, pp. 28-29 i M.T. FERRER I MALLOL, Les aljames sarraines, p. 16.

25 ACA, C, reg. 127, f. 52 r. (1303, abril, 1). Cit a M.T. FERRER I MALLOL, Organització i defensa d'un territori fronterer. La Governació d'Oriola en el segle XIV, Barceiona, Institució Milà i Fontanals. CSIC, 1990, p. 42. 
Per això el rei es veié obligat a autoritzar l'arrais de Crevillent a fer tornar els moros que eren a la bastida de Mula per tal que poguessin defensar la seva terra ${ }^{26}$. A més li donà una credencial perquè s'adrecés a tots els moros de Múrcia amb un missatge reial, que no sabem quin devia ésser, però que segur que tenia relació amb aquests problemes ${ }^{27}$.

La contribució a la guerra pesà també sobre la població sarraïna, igual que sobre la població cristiana. Si bé al començament els seus serveis no foren gaire requerits, almenys no pas mentre hi hagué a la regió l'exèrcit que portà a terme la part més important de la conquesta, després la reducció dels efectius provinents dels altres regnes obligà a recórrer als habitants del regne de Múrcia per a mantenir la defensa i per a portar a terme alguna de les campanyes; com els altres súbdits del regne, quedaren obligats a la prestació del servei d'host durant dos mesos. Pel gener de 1298, tenim constància que, als sarraïns d'Alacant, els fou perdonat aquest servei d'host a canvi de traslladar de manera cuitada, de nit i de dia, tota la fusta i aparells d'un giny que es trobava a Alacant fins al setge d'Alhama, mentre que els moros de Múrcia, els d'Oriola, els d'Elx i els d'Alcantarilla foren convocats per ajudar en aquesta tasca i a més per portar-hi una perxa que el rei havia fet tallar a Múrcia ${ }^{28}$.

Però no és fins a l'època de govern del procurador Bernat de Sarrià que les notícies són més abundoses, precisament per l'esforç de guerra que demanà i que provocà queixes en tot el regne ${ }^{29}$. L'any 1301 , sabem que els moros d'Elda, Novelda i Elx foren convocats a l'exèrcit a Mula, però finalment els d'Elda i Novelda aconseguiren la remissió d'aquesta obligació a canvi del pagament de 7.000 sous; havien al.legat, per deslliurarse, la seva pobresa, de manera que hem de suposar que el servei militar els resultava molt més carregós que aquella quantitat, que a més no havien de pagar de manera immediata sinó que tenien temps fins el 24 de juny ${ }^{30}$. L'any 1303 ja hem vist que els moros d'Elx participaven en el setge de Mula i sabem que també ho havien fet els moros d'Alacant; però aquests, pel desembre de 1302, n'havien marxat, sense autorització, fatigats pel llarg setge, i el rei havia hagut de demanar al procurador Bernat de Sarrià que els rebaixés la multa de 100 sous que els havia imposat, perquè no la podien pagar ${ }^{31}$.

Hi havia, encara, altres obligacions militars, les preventives. A Oriola i a Múrcia els sarraïns havien estat obligats, l'any 1302, a col-laborar en el servei d'escoltes i guardes a cavall per a vigilar els camins. Pel gener d'aquest any els moros oriolans protestaven perquè deien que no era costum que ho haguessin de fer, mentre que a

26 ACA, C, reg. 127, f. 52 r.-v. (1303, abril, 1).

27 ACA, C, reg. 307, f. 88 v. (1303, març, 30), publ. per J. M. del ESTAL, El reino de Murcia bajo Aragón, $\mathrm{I} / 2$, docs. 224-225.

28 ACA, C, reg. 253 , f. 71 v. i reg. 256 , f. 6 v. $(1298$, gener, 19 i 24)

29 Sobre el govern de Bernat de Sarrià cf. M.T. FERRER, Organització i defensa d'un territori fronterer, pp. 23-48, especialment pp. 27, 39 i 41-42.

30 ACA, C, reg. 332, f. 127 v. i 129 r. (1301, gener, 3, 11, 14, 18), publ. per J. M. del ESTAL, El reino de Murcia bajo Aragón, $1 / 2$, docs. 146, 148, 154, 156 i 160.

31 ACA, C, reg. 126, f. 190 r.-v. (1302, desembre, 23). 
Múrcia no tenim constància de cap protesta verbal, però sí de fet: marxaven de la ciutat. La reacció de Jaume II fou demanar al procurador que cessés de fer-los exaccions que no podien pagar, perquè no volia que la Reixaca es despoblés ${ }^{32}$.

L'interès per a mantenir la població sarraïna del regne fou visible, a l'obra de govern de Jaume II, des d'un primer moment. Com anirem veient, concedí guiatge als sarraïns que residien al regne $\mathrm{i}$ algunes franquícies temporals d'impostos, extensives també als moros que s'hi establissin. Calia que l'economia del regne tornés a posar-se en marxa després del trasbals de la guerra i de moment, atesa l'escassedat de la població cristiana, els sarraïns eren imprescindibles, especialment a l'àmbit rural, però també per a molts oficis artesanals.

\section{LES COMUNITATS DEL REGNE DE MÚRCIA DURANT LA GUERRA}

\section{Alacant}

Alacant tenia una moreria urbana força reduïda a la darreria del segle XIII; la causa, segurament cal buscar-la en el fet que era una de les viles que s'havien resistit al protectorat castellà imposat pel pacte d'Alcaraz del 1243 i on l'exèrcit d'Alfons el Savi, llavors infant, intervingué amb contundència. Probablement ja llavors la població islàmica sofrí una reducció molt important i segurament fou desposseïda de la terra, puix que tant els documents alfonsins ${ }^{33}$ com els posteriors, quan es refereixen als moros de l'horta d'Alacant, esmenten sempre eixàrics, és a dir, moros que no tenien terres pròpies i que conreaven les dels cristians, amb dret a una part dels fruits. Segons les al.legacions presentades pel justícia d'Alacant en un procés contra sarraïns per homicidi, l'any 1315, els moros que residien a l'horta d'Alacant eren tots eixàrics; cap no tenia heretatges propis, a diferència dels sarraïns d'Elx, d'Oriola o de la vall d'Elda, i eren considerats domèstics dels senyors de qui tenien heretats ${ }^{34}$.

A causa de la sublevació contra el domini castellà el 1264, la comarca d'Alacant degué resultar molt castigada per les ràtzies de l'infant Pere, després Pere el Gran. La conquesta de Jaume I, el 1265-1266, degué acabar de delmar la població mora, especialment en un lloc de pas obligat com Alacant.

La guerra amb Castella, que començà el 1296, trobà, doncs, una població sarraïna afeblida. Davant la perspectiva d'una nova guerra, una part dels moros d'Alacant es refugiaren a Crevillent, com ja hem dit.

Quan la comarca alacantina tornà a quedar assossegada, després de la conquesta per Jaume II, els sarraïns d'Alacant mostraren interès a tornar a llur lloc d'origen i el

32 ACA, C, reg. 120, f. 233 r.-v. (1302, gener, 23) i reg. 124, f. 190 v. (1302, juny, 7). M.T. FERRER, Organització $i$ defensa d'un territori fronterer, pp. 41 i 42.

33 J. TORRES FONTES, La reconquista de Murcia, pp. 37-44 i Colección de documentos para la Historia del reino de Murcia, III. Fueros y Privilegios de Alfonso X el Sabio al reino de Murcia, ed. per J. TORRES FONTES, Múrcia, 1973, pp. LI-LXI i docs. 23, 39, 55, 59 i 60.

34 M.T. FERRER I MALLOL, «Un procés per homicidi entre sarraïns de l'Horta d'Alacant», Sharq al-Andalus, 7 (1990), p. 146. 
seu propòsit fou facilitat pel mateix rei, que concedí guiatge a tots els que s'establissin a I'horta d'Alacant i hi residissin personalment.

Per tal d'incrementar la població sarraïna, Jaume II concedí, a més, franquícia de peita $o$ alfarda durant dos anys als moros que s'establissin a Alacant. Els autoritzà a elegir un altre alamí, si no estaven contents del que tenien, i concedí que l'alamí jutgés les seves causes segons sunna, tal com s'havia fet fins llavors. El rei disposà, a més, que no poguessin ser obligats a fer obres al castell d'Alacant i que tampoc no els poguessin ser confiscats els animals de càrrega per al mateix objectiu. Prohibí a l'alcaid del castell que intervingués en res que els afectés, ja que era el batlle d'Alacant qui se n'havia d'ocupar, i li ordenà que retornés als sarraïns alacantins el bestiar que els havia confiscat pretextant que era de gent d'Elx, els quals estaven en guerra amb Jaume $\|^{35}$.

Potser el raval on vivien els sarraïns d'Alacant resultà destruït per la guerra o potser les autoritats locals consideraren més oportuna una altra ubicació, el cas és que sabem que el 1303 es construïa de nou un raval dels sarraïns a Alacant; sembla que algunes persones en pertorbaven l'edificació perquè pretenien tenir drets en el terreny escollit i calgué que el rei intervingués en la qüestió per encomanar la resolució del litigi a uns prohoms que havien de ser nomenats pel justícia i pels jurats d'Alacant ${ }^{36}$.

Les nostres notícies sobre el nombre aproximat de sarraïns residents a Alacant i al seu terme són molt migrades i es basen en les xifres del cabeçatge. En el meu llibre sobre les aljames sarraïnes de la governació d'Oriola, les vaig analitzar i vaig arribar a la conclusió que, entre el raval i l'horta, els moros d'Alacant no sobrepassaven el miler ${ }^{37}$.

El cabeçatge era l'impost que pagaven els caps de família o membres del mateix grup familiar que tenien béns propis o edat per a treballar. L'any 1261 Alfons $X$ havia concedit aquest tribut al consell d'Alacant, perquè l'esmercés en la construcció de les muralles $i$ en altres despeses municipals ${ }^{38}$; però, com que no havia esmentat totes les diverses categories de contribuents, resultà que els peons de l'horta i les mores vídues de la vila quedaven fora d'aquell privilegi i els trobem pagant el cabeçatge al batlle general, mentre que la resta dels sarraïns, els eixàrics i els botiguers i menestrals, en teoria, l'havien de pagar directament al municipi d'Alacant. Diem en teoria perquè, els anys 1256 i 1257, Alfons el Savi havia concedit als amos cristians que tenien eixàrics sarraïns a les seves terres el delme, l'alfatrà i el cabeçatge dels seus moros ${ }^{39}$.

La contradicció entre els diferents privilegis i la multiplicitat de perceptors del cabeçatge provocà plets entre la vila d'Alacant i diversos senyors. El 1298 n'hi havia un entre Vicenç de Xixona, propietari d'unes alqueries dins el terme d'Alacant per

35 P. GUICHARD, Un señor musulmán en la España cristiana, p. 27, i M.T. FERRER I MALLOL, Les aljames sarraïnes, pp. 53-54, 66-67.

36 ACA, C, reg. 127 , f. 108 r. (1303, abril, 24).

37 M.T. FERRER, Les aljames sarraines, pp. 53-54.

$38 \mathrm{lbidem}$, docs. 59 i 60 .

39 Colección de documentos de Murcia, III, docs. 23 i 39. 
donació de Jaume II, i la vila d'Alacant. Vicenç de Xixona assegurava que els sarraïns de les seves alqueries mai no havien pagat el cabeçatge als homes d'Alacant en temps dels anteriors propietaris, que eren García Fernández de Varea i la seva muller dona Elis i després Fernando Rodríguez de Aranguren, mentre que els homes d'Alacant pretenien que els pertocava aquest dret ${ }^{40}$. Creiem que aquestes alqueries eren les d'Alconchel i Aljucén, a l'horta d'Alacant, prop del Moliniello, segurament dins el terme actual de Mutxamel, ja que sabem que limitaven amb la muntanya de Busot ${ }^{41}$. El mateix problema sobre el pagament del cabeçatge es presentà posteriorment també a Agost, cosa que fa pensar que el privilegi d'Alfons el Savi potser no havia tingut una efectivitat real, almenys a les alqueries ${ }^{42}$.

Diverses fonts, algunes de posteriors als anys que estudiem, ens informen de la presència de sarraïns en algunes alqueries de l'horta, Canyelles o Benifageig, Benialí, Benimocrén etc. ${ }^{43}$.

Als llogarrets més grans, els tenim documentats a Agost, a Busot, d'on van marxar tots cap a Granada el 1304, seguint en la retirada els genets granadins que havien envaït aquelles terres meridionals valencianes ${ }^{44}$, i a Nompot 0 Montfort ${ }^{45}$.

Malgrat l'interès de Jaume II i dels seus successors per a afavorir la residència de moros a Alacant i al seu terme, la comunitat sarraïna mostrà una progressiva tendència a disminuir. La invasió dels genets granadins, que es produí el 1304, precipità aquesta tendència perquè molts sarraïns de les comarques meridionals valencianes marxaren a Granada amb ells. Més tard, la guerra amb Castella dels dos Peres accentuà la despoblació.

\section{Elx}

Elx era una vila important i rica i també la que tenia un nucli més important de població sarraïna. Pertanyia, en el moment de la conquesta, a don Juan Manuel, de la família reial castellana ${ }^{46}$. Malgrat que, quan van iniciar-se les operacions militars, no fou atacada perquè hi havia negociacions obertes amb don Juan Manuel per al reconeixement de Jaume II com a rei de Múrcia, el fracàs final d'aquestes negociacions provocà que el lloc fos assetjat des del començament del mes de juny de 1296 fins al 27 de juliol, en què se signà una treva que hauria de durar alguns anys.

Com a Alacant, abans que Jaume II no iniciés les operacions militars contra Elx, un bon nombre de sarraïns van abandonar el lloc i es van refugiar a Crevillent, sota la protecció de l'arrais, i a Alacant. Jaume II els concedí dos guiatges, un el 24 de maig

40 ACA, C, reg. 107, f. 251 r. (1298, febrer, 9).

41 Cf. els límits a ACA, C, reg. 340, f. 28 v. (1296, maig, 7).

42 M.T. FERRER, Les aljames sarraines, p. 14 i doc. 72.

43 M.T. FERRER, Un procés per homicidi entre sarraïns de l'Horta d'Alacant, pp. 145-146.

44 M.T. FERRER, Les aljames sarraïnes, p. 54.

45 Ibídem, p. 55.

46 Cf. sobre aquesta etapa: J. HINOJOSA MONTALVO, La morería de Elche en la Edad Media, Terol, Centro de Estudios Mudéjares. Instituto de Estudios Turolenses, 1994, pp. 7-16. 
i un altre el 5 d'agost, aquest darrer perquè poguessin tornar als seus domicilis ${ }^{47}$. El 20 d'agost, Jaume II confirmà als sarrainns d'Elx els privilegis $i$ les donacions que els havien concedit l'infant Manuel $i$ el seu fill don Juan Manuel fins a la data ${ }^{48}$. A més, recomanà al seu germà Jaume Pere, procurador del regne de Múrcia, que els defensés contra qualsevol que intentés maltractar-los i que no els fes pagar cap impost que no paguessin en temps de l'infant don Manuel. Aquell mateix mes d'agost els autoritzà a portar i vendre per tots els seus dominis blat, oli i altres mercaderies, pagant lleudes, peatges i altres drets acostumats, i manà als homes d'Elx que haguessin rebut comandes de sarraïns abans del setge que els les restituïssin ${ }^{49}$.

Basant-me en les informacions que proporcionen els impostos del cabeçatge i de gallines, que no són exactes, vaig calcular que Elx i la seva rodalia tenien de 2.100 a 2.450 habitants sarraïns cap al 1315. Poser eren més en el moment immediatament posterior a la conquesta. A part de la pèrdua de població que pogué suposar la guerra, la incursió de l'exèrcit de Granada, l'any 1304, també tingué una repercussió negativa, ja que sabem que hi havia sarraïns d'Elx entre els que van seguir l'exèrcit nassarita a la retirada.

A Elx, els sarraïns vivien en un raval situat a la part meridional de la vila, al voltant d'una mesquita, ara església de Sant Joan. Bé que una part dels habitants del raval devien dedicar-se a oficis artesanals, sembla que molts vivien de l'agricultura i treballaven terres a cens del rei o del senyor del lloc, a la porció del terme dita Magram.

L'abundància de privilegis i disposicions reials a favor d'aquesta aljama palesen la importància que tenia. Ja el 20 d'agost de 1296, Jaume II confirmà tots els privilegis que li havien estat concedits per l'infant Manuel i pel seu fill don Juan Manuel, però fou l'any 1303 quan el monarca féu un major nombre de concessions: ordenà el respecte dels privilegis que havia confirmat anteriorment i a més concedí als sarraïns que no poguessin ser convocats a exèrcit, llevat del cas que el regne de Múrcia fos envaït per un gran nombre d'enemics i calgués el seu ajut o que ell els ho manés expressament; els concedí igualment que ni cap oficial reial de Múrcia, ni cap cavaller no els pogués prendre les bèsties per portar-les a l'exèrcit; aquesta concessió fou confirmada el 1318, afegint-hi que fins i tot el rei hauria de pagar lloguer per les bèsties que requisés; els condonà el pagament de l'algarfa, que era un dels impostos que gravaven els fruits de la terra, i suprimí la tarcana, que sembla que era un bordell; concedí, als sarraïns que s'establissin a Elx o que hi acudissin a comerciar, que fossin jutjats en les seves causes i plets com els del lloc en igual cas i, per tal d'atreure pobladors sarraïns, concedí franquícia de cabeçatge i d'alfarda durant un any als sarraïns francs que s'hi establissin ${ }^{50}$.

47 M.T.FERRER I MALLOL, "La conquesta de les comarques meridionals valencianes per Jaume Il», en curs de publicació a Quaderns del Migjorn; M.T. FERRER, Les aljames sarraïnes, p. 51.

48 J. del ESTAL, Vasallaje, doc. III; M.T. FERRER, Les aljames sarraïnes, p. 60 i doc. 69; J. del ESTAL, El reino de Murcia bajo Aragón, $\mathrm{l} / 2$, doc. 18, amb algunes incorreccions a la transcripció dels noms dels testimonis.

49 ACA, C, reg. 104, f. 45 v. (1296, agost, 20).

50 M.T. FERRER, Les aljames sarraïnes, pp. 47-51 i 60-61. 
Aprofitant el canvi de senyoriu, cristians, jueus i sarraïns d'Elx intentaren escapolirse de l'obligació de pagar delmes i primícies a la seu de Cartagena, però no aconseguiren aquest objectiu, malgrat les males relacions del rei amb el bisbe de Cartagena $i$ altres alts càrrecs eclesiàstics ${ }^{51}$.

Durant els primers mesos de l'any 1303, els sarraïns d'Elx degueren queixar-se de transgressions dels seus usos i costums, perquè Jaume II procurà acontentar-los i féu expedir el mateix dia, el 25 d'abril, tot un seguit de concessions o de recomanacions al batlle general perquè s'informés més a fons de les queixes per tal de poder decidir amb coneixement de causa. Manà, en primer lloc, als col-lectors dels drets d'actuar amb tota la benignitat que els fos possible amb els sarraïns d'Elx $i$, al batlle general, li ordenà que només els fes pagar cena per al batlle reial una vegada a l'any i no més, com sembla que se'ls exigia, bé que li manava que primer se n'informés. Per a algunes qüestions, els sarraïns d'Elx retreien com a model els temps de l'infant Manuel: s'havien queixat, per exemple, que llavors no pagaven un impost anomenat merinat, que havia creat don Juan Manuel per cobrir la despesa de gent a cavall per a la guarda del lloc; però, per altra banda, es queixaren que ja en temps de l'infant eren obligats a pagar redempció d'exèrcit, "tarif» $i$ «bera», malgrat que en general els sarraïns no estaven obligats a redempció d'exèrcit; es lamentaven que sota el domini de Jaume Il continuaven aquesta mena d'exaccions; també es queixaven que, quan hom els demanava peites i exaccions, tots eren taxats a abonar-ne una certa part però, com que alguns se n'anaven del lloc sense pagar, la resta era obligada a satisfer la seva part, cosa que trobaven molt injusta; també protestaven perquè hom els exigia impostos de trànsit que abans no pagaven: els demanaven 7 sous si es traslladaven a Múrcia, Lorca o Granada, quan passaven per Oriola, i havien d'abonar 15 diners per cada càrrega d'oli, quan abans només en pagaven un diner lleonès; es planyien encara de ser molestats en l'empriu de les aigües i s'exclamaven d'haver de pagar el delme d'una manera que els resultava més carregosa i cara que abans. Abans, deien, quan anaven a començar la sega o la verema, avisaven els delmers perquè anessin a les eres i a les vinyes a rebre el delme, mentre que ara els delmers no hi volien anar i els demanaven el preu del delme més tard i més car; sembla que els sarraïns d'Elx s'havien queixat de falta d'observança del privilegi concedit per l'infant Manuel, pel qual si un sarraí era processat, havia d'estar pres a la presó dels sarraïns. Aquestes dues darreres qüestions, el rei les atorgà sense més formalitats, mentre que per a la resta en demanà al batlle general més información ${ }^{52}$.

Alguns mesos més tard, a la darreria de novembre, fou don Juan Manuel mateix qui denuncià intromissions del procurador del regne de Múrcia, Pere de Montagut, en els afers dels moros d'Elx i del seu terme i en els dels moros d'Asp, de Xinosa i de Monòver. Com que Jaume II desitjava mantenir els pactes amb don Juan Manuel, manà a Pere de Montagut que no hi intervingués ${ }^{53}$.

51 ACA, C, reg. 107, f. 222 r. (1299, febrer, 9). El rei es mostrà disposat, més endavant, l'any 1302, a fer estudiar la revisió d'un conveni entre don Juan Manuel i el capítol de Cartagena sobre el pagament del delme: reg. 125, f. 116 r.-v. (1302, octubre, 20).

52 ACA, C, reg. 127, ff. 108 r.-109 v.

53 M.T. FERRER, Organització $i$ defensa d'un territori fronterer, p. 54. 
Del funcionament intern de l'aljama d'Elx en el moment immediatament posterior a la conquesta, no en tenim gaires referències; és més tard, però encara dins del regnat de Jaume II, que les notícies comencen a sovintejar. No m'hi referiré, doncs, ara perquè, a més, tot el que en sé ja ho vaig exposar al meu llibre ${ }^{54}$.

A l'horta d'Elx hi havia moltes alqueries habitades per sarraïns: algunes, com les de Marxena, Terça i Benicuei, devien formar part de l'aljama del raval, però altres, com les de Tres Espilles, Xàrquia i l'Asprella, sembla que formaven aljama a part; hi havia a més algunes alqueries senyorials, com la de Beniabez, o les de Beniamor i Saoní o Saonei, que pertanyien a l'arrais de Crevillent; tenim encara notícia de les de Rabat, Beniboc etc., però són notícies molt poc explícites ${ }^{55}$.

\section{Crevillent}

Crevillent era el centre del senyoriu de la família ibn Hudayr. Pierre Guichard ha estudiat aquesta família, la seva influència, les seves possessions ${ }^{56}$; el Prof. del Estal i jo mateixa hem afegit noves dades per al coneixement d'aquest senyoriu singular. En el moment de la conquesta per Jaume Il ostentaven el títol d'arrais de Crevillent Ahmad i Muhammad, que eren oncle i nebot ${ }^{57}$. Tant l'un com l'altre mostraren bona predisposició a acceptar la senyoria de Jaume II i a fer-la acceptar pels sarraïns de les localitats veïnes. El 17 de maig, Muhammad reconegué Jaume II com a rei, després de les negociacions dutes a terme per Ahmad $i$, el 23, el rei confirmà a aquest darrer la possessió de Crevillent, Coix i Albatera i, a més, concedí Beniopa, prop de Gandia, amb caràcter vitalici segons uns documents a Ahmad $i$ segons uns altres a Muhammad ${ }^{58}$.

Com ja he dit, Crevillent es convertí en refugi dels sarraïns d'Oriola, d'Albatera, de Coix, d'Elx i d'Alacant, que temien ser victimes dels abusos dels soldats. L'arrais Muhammad fou autoritzat pel mateix rei a assegurar les persones $i$ els béns dels sarraïns que tornaven als llocs de residència, amb la condició que reconeguessin prèviament Jaume II com a rei de Múrcia, cosa que investia l'arrais d'una gran autoritat, mentre que l'altre arrais, Ahmad, era honorat amb el càrrec de jutge dels sarraïns del

54 M.T. FERRER, Les aljames sarraïnes, pp. 61-63.

55 M.T. FERRER, Les aljames sarraïnes, pp. 12-13 i 64-65.

56 P. GUICHARD, Un señor musulmán en la España cristiana, ja citat.

57 Quan, a la darreria de desembre de 1297, Ahmad morí, Jaume Il donà el condol a Muhammad per la mort —diu el document- del seu oncle: ACA, C, reg. 107, f. 178 v. (1298, gener, 3). P. Guichard no havia pogut aclarir el parentiu entre l'un arrais i l'altre: P. GUICHARD, Un señor musulmán en la España cristiana, quadre genealògic dels Banu Hudayr, p. 85. També desconeixia la data de la mort d'Ahmad.

58 ACA, C, reg. 25, f. 282 r.-v. publ. per P. GUICHARD, Un señor musulmán en la España cristiana, doc. 1 i pp. 22-23; i reg. 340, f. 107 r. i 108 r.-v. publ. J. M. del ESTAL, Vasallaje del señorio musulmán de Crevillente, docs. VI I IX i El Reino de Murcia, 1/2, docs. 49-50. M.T. FERRER, Les aljames sarraines, p. 17. Sobre el senyoriu dels lbn Hudayr a Beniopa cf. M.V. FEBRER ROMAGUERA, «EI señorío mudéjar de Beniopa (Valencia) en la época de sus arraeces de la familia de ibn Hudayr (12961322)", a IV Simposio Internacional de Mudejarismo: Economía, pp. 351-361. 
regne de Múrcia, des d'Oriola a Alacant i Beniopa, càrrec que sembla que ja havia tingut precedentment. Jaume II confià, a més, a Ahmad, el 4 de juny, els llocs d'Asp, de Monòver i de Xinosa, que es devien haver retut gràcies a la seva mediació ${ }^{9}$.

També li foren confirmats, de manera genèrica, els béns que posseïa a la capital i els que hi tenia la seva muller Abnatalaziz per donació del seu pare, l'exrei sarraí de Múrcia, Muhammad ibn Huddo; més tard, el rei confirmà a l'arrais Ahmad: deu caps de moros eixàrics a la mateixa ciutat, que tenia per concessió dels reis de Castella ${ }^{61}$, i unes cases a la Reixaca que havia comprat a la vídua d'un tal "Suayach», moro de Múrcia, que havien estat confiscades a causa d'una informació proporcionada per Juan Pérez de Tarazona i donades a aquest, provisions que foren anul-lades quan l'arrais es queixà ${ }^{62}$.

Ignorem quines prerrogatives foren reconegudes als arrais de Crevillent; els documents diuen que eren les mateixes que tenien reconegudes en temps passats, és a dir, sota el domini dels reis de Castella. Suposem que devien consistir en cessió d'impostos i de drets jurisdiccionals semblants als que la Corona cedia en senyorius cristians. Dins el pla militar, l'arrais de Crevillent figurà en lloc destacat, per la importància de la seva comitiva - dos cavalls armats i entre vuit i quatre cavalls alforrats-, a la llista dels homes que servien el rei amb cavalls a la frontera ${ }^{63}$.

Probablement els privilegis de què gaudien els arrais devien semblar a alguns nobles i alts oficials poc adequats a llur condició de sarraïns. Pel novembre de 1297, el rei hagué d'advertir al seu germà Jaume Pere, procurador del regne de Múrcia, que fes respectar els béns i privilegis confirmats a l'arrais Ahmad de Crevillent, que es queixava del tracte que rebia. Uns quants anys després, el 1301, calgué fer una recomanació semblant a favor de l'arrais Muhammad ${ }^{64}$.

59 P. GUICHARD, Un señor musulmán en la España cristiana, pp. 23 i 28-29. J.M. del ESTAL, Conquista y anexión de las tierras de Alicante, Elche, Orihuela y Guardamar al reino de Valencia por Jaime // de Aragón (1296-1308), Alacant, Publicaciones de la Obra Social y Cuitural de la Caja de Ahorros Provincial de Alicante, 1982, doc. 5; Vasallaje del señorio musulmán de Crevillente, doc. XI, i El reino de Murcia bajo Aragón, 1/1, doc. 79; M.T. FERRER, Les aljames sarraïnes, pp. 16-17 i docs. 6 , 7, 13; J.M. del ESTAL, El reino de Murcia bajo Aragón, 1/2, docs. 51 i 58, aquest darrer amb una regesta que no es correspon exactament al contingut del document.

60 ACA, C, reg. 340, f. 107 r.-v. (1296, maig, 23); Cit. per P. GUICHARD, Un señor musulmán en la España cristiana, p. 28 i M.T. FERRER, Les aljames sarraïnes, p. 17. El document de confirmació dels béns d'Abnatalaziz ha estat publicat per J. M. del ESTAL, Vasallaje del señorio musulmán de Crevillente, doc. VIII, i El reino de Murcia, I/2, doc. 52.

61 ACA, C, reg. 106, f. 129 r. (1297, desembre, 7).

62 ACA, C, reg. 106, f. 101 r. (1297, novembre, 27), però el rei féu que els alcadís i jurisperits cristians de Múrcia informessin sobre la qüestió: ACA, C, reg. 106, f. 117 r. (1297, desembre, 5).

63 P. GUICHARD, Un señor musulmán en la España cristiana, p. 30, i M.T. FERRER, "La tinença a costum d'Espanya en els castells de la frontera meridional valenciana (segle XIV)", Miscel.lània de Textos medievals, 4. La frontera terrestre i marítima amb I'lslam, Barcelona, CSIC.Institució Milà i Fontanals, 1988, doc. 4 i M.T. FERRER, Organització i defensa d'un territori fronterer, doc. 32 . El nombre de cavalls alforrats era de vuit a l'ordinació del primer de maig de 1303 i fou rebaixada a quatre a la del 18 de maig.

64 M.T. FERRER, Les aljames sarraïnes, p. 17. 
Després de la mort d'Ahmad, continuà com a arrais el seu nebot Muhammad, mentre que el fill d'Ahmad, Muhammad, veia reconegudes tant la dignitat d'arrais com les propietats del seu pare, Crevillent, Coix, Albatera i els béns de Múrcia, bé que l'altre Muhammad continuà ostentant el títol d'arrais. La identitat de nom fa difícil destriar les activitats de l'un i de l'altre, però creiem que fou el més gran qui tingué el govern efectiu de Crevillent i qui fou nomenat, l'any 1301, jutge dels sarrains de la Reixaca de Múrcia i, el 1305, jutge dels sarraïns de les terres dellà Xixona. També degué ser ell mateix el destinatari d'una carta en la qual Jaume II, abans d'emprendre un viatge per a entrevistar-se amb el Papa, l'any 1305, deia que comptava amb ell per tal de guardar la terra durant la seva absència ${ }^{65}$.

Efectivament, després de la conquesta del regne de Múrcia, el paper de l'arrais de Crevillent continuà essent molt important com a intermediari amb Granada 0 com a font d'informació sobre les intencions de la cort granadina, on l'arras, per indicació de rei o per iniciativa pròpia, enviava sovint emissaris o espies ${ }^{66}$. L'any 1318 , el senyoriu fou annexionat a la Corona.

El fet que Crevillent fos lloc de senyoriu fa que no tinguem dades ni de població ni pràcticament d'activitats, ja que ens manca la documentació fiscal que, encara que sigui de manera ocasional, trobem en altres casos.

\section{La vall d'Elda}

Monòver i Xinosa. Ambdós llocs, i la torre de Salines, havien pertangut a don Juan Manuel. Durant la conquesta del regne de Múrcia foren ocupats per Ferran Garcés de Rueda. No tenim constància que els habitants sarraïns d'aquests llocs rebessin cap guiatge fins que Jaume II no en concedí un, el darrer dia de juliol de 1296, a tots els sarraïns que anessin a residir al regne de Múrcia i, en particular, a Elx, Xinosa, Monòver i Salines, mentre paguessin els drets acostumats ${ }^{67}$. Jaume II confià, de moment, tots dos llocs a l'arrais de Crevillent, però després de la partició del regne de Múrcia, l'any 1304, de la delimitació i de la pèrdua de la propietat d'aquests llocs per part de don Juan Manuel, Jaume II els concedí, amb caràcter vitalici, al seu conseller Gonçalvo Garcia ${ }^{68}$.

Monòver i Xinosa, com a llocs de senyoriu, són pobres en documentació fiscal i, per tant, no tenim dades de població ni pràcticament d'activitats. Sabem només que l'any 1301 el rei volia recaptar en aquests dos llocs i a Asp l'impost de la cena, que havia cobrat en passar per Elx, però que amb les presses per arribar a Múrcia no havia pogut demanar-lo a aquests altres llocs ${ }^{69}$.

65 M.T. FERRER, Les aljames sarraines, pp. 16-18. Doc.de confirmació a favor de Muhammad II publ. per J. M. del ESTAL, El reino de Murcia, 1/1, doc. 158, i 1/2, doc. 105, on no se cita ni a ell mateix.

66 M.T. FERRER, Les aljames sarraines, pp. 16-18.

67 M.T. FERRER, Les aljames sarraines, p. 22 i doc. 16.

68 M.T. FERRER, Les aljames sarraïnes, pp. $22-23$.

69 ACA, C, reg. 332, f. 129 v. (1301, gener, 24), publ. per J. M. del ESTAL, El reino de Murcia bajo Aragón, 1/2, doc. 161. 
Petrer. Petrer, un llogarret de població predominantment sarraïna, era domini de la família Garcia de Loaysa el moment de la conquesta del regne de Múrcia per Jaume II i continuà a les seves mans. Malgrat que Joan Garcia de Loaysa semblava disposat a reconèixer Jaume II, finalment allargà la prestació d'homenatge perquè volgué fer-la de manera acordada amb don Juan Manuel i especialment amb Violant Manuel, germana de don Juan Manuel i el seu marit, l'infant Alfons de Portugal, dels quals era procurador a les seves poblacions d'Elda i Novelda. Finalment prestà homenatge el 4 de juny de 1296, però des del mes d'abril era sota guiatge ${ }^{70}$. El fet que Petrer no entrés a la guerra i estigués sota guiatge pràcticament des del començament de les operacions militars, estalvià als seus habitants molts sofriments. El 5 de juny, després del reconeixement de Jaume II per Garcia de Loaysa, els moros de Petrer reberen un nou guiatge, el definitiu ${ }^{71}$.

Sembla, però, que els sarraïns van considerar la guerra com una mena d'alliberament total de les seves obligacions anteriors respecte a Joan Garcia de Loaysa, que devien conceptuar persona lligada al règim anterior, i es negaren a pagar-li les peites i els tributs deguts a l'alcaid. La reacció del rei fou la de donar suport a l'autoritat de Joan Garcia de Loaysa $\mathrm{i}$ ordenà als seus oficials que obliguessin els moros a pagar ${ }^{72}$.

Com que Petrer era lloc de senyoriu, no tenim dades ni de població ni pràcticament d'activitats, ja que ens manca la documentació fiscal, com ens passa a Crevillent, a Monòver i a Xinosa. Sabem, però, que els Loaysa tingueren dificultats per a mantenir la població sarraïna dins el seu domini. El 1309, els moros de Petrer feren arribar queixes a Jaume II perquè Joan Garcia no respectava els privilegis atorgats pels seus antecessors i per ell mateix i no els permetia de vendre llurs propietats ni traslladar-se a viure al domini reial ${ }^{73}$. Probablement, les ofertes de rebaixes d'impostos als qui s'establissin a les moreries reials havien causat impacte a Petrer.

Elda i Novelda. En el moment de la conquesta del regne de Múrcia per Jaume II, Elda i Novelda pertanyien a la infanta Violant, esposa de linfant Alfons de Portugal. La sentència arbitral de Torrellas del 1304, que acabà la guerra, atribuí aquests llocs a Jaume II i es pactà una indemnització per als infants de Portugal, a càrrec del rei de Castella ${ }^{74}$.

No tenim notícia de concessió de privilegis a aquests dos llocs reials, fora d'un guiatge concedit el 1296 als sarraïns d'Elda i Novelda, mentre el rei negociava que els infants de Portugal el reconeguessin com a rei de Múrcia $^{75}$.

70 M.T. FERRER I MALLOL, «La conquesta de les comarques meridionals valencianes per Jaume II", en curs de publicació a Quaderns del Migjorn.

71 J. M. del ESTAL, El Reino de Murcia bajo Aragón, 1/1, doc. 59.

72 ACA, C, reg. 340, f. 157 r. (1296, juny, 20).

73 M.T. FERRER, Les aljames sarraïnes, p. 78.

74 A. GIMÉNEZ SOLER, Don Juan Manuel, pp. 34-35 i docs. CVII, CVIII, CX, CXI, CXVI, CXXVII i CXXXVIII, J. M. del ESTAL, Obra de los reyes D. Dionís e Isabel de Portugal y de los infantes $D$. Alfonso y $D^{a}$ Yolanda Manuel en la conquista y sumisión del Reino de Murcia a la Corona de Aragón, a «Actas das II Jornadas Luso-Espanholas de História Medieval", I, Porto, 1987, pp. 147-158, i M.T. FERRER, Les aljames sarraines, pp. 32-33.

75 M.T. FERRER, Les aljames sarraïnes, doc. 14. 
Joan Garcia de Loaysa, el senyor de la veïna població de Petrer, a qui ens acabem de referir, actuava com a procurador dels infants i es va trobar aquí amb el mateix problema que havia hagut d'afrontar a Petrer i que ja hem comentat, és a dir, que els sarraïns es van considerar alliberats per la guerra de complir les seves obligacions anteriors respecte a Joan Garcia de Loaysa, que era l'alcaid de tots dos llocs, i es negaren a pagar-li les peites i els tributs deguts per aquest càrrec. La reacció del rei, com ja hem dit, fou la de donar suport a l'autoritat de Joan Garcia de Loaysa també a Elda i a Novelda i ordenà als seus oficials que obliguessin els moros a pagar ${ }^{76}$.

Malgrat aquest intent de defugir la seva autoritat, Joan Garcia de Loaysa continuà preocupant-se pels moros d'Elda i Novelda i, pel setembre, demanà protecció per a ambdós llocs. Jaume II la concedí i ordenà al seu germà Jaume Pere, procurador del regne de Múrcia, que no permetés que se'ls fes cap mal7 ${ }^{77}$. No coneixem cap altra intervenció reial a favor dels moros d'Elda i de Novelda fins al febrer de 1301, en què manà a Bernat de Sarrià, llavors procurador del regne, que els tractés favorablement i els defensés ${ }^{78}$. Dos anys després, pel juny de 1303, hagué d'amonestar el nou procurador, Pere de Montagut, perquè els demanava exaccions inusuals ${ }^{79}$.

L'administració de les rendes d'Elda i de Novelda durant el període de la guerra comportà alguns problemes. Sembla que el responsable de la gestió dels comptes fou Huçmen Abencaçila o Abentaçila, sarraí de Novelda. Al començament de l'any 1301, Jaume II l'havia convocat i li havia atorgat guiatge sens dubte per a parlar d'aquesta qüestió ${ }^{80}$; poc després, el rei manà als moros d'Elda i de Novelda de posar a la disposició de l'infant Alfons de Portugal els 7.000 sous reials de Múrcia que ell els havia demanat anteriorment ${ }^{81}$; però les dificultats varen venir després de la pau amb Castella, perquè l'infant de Portugal volia cobrar les seves rendes endarrerides i demanava a Garcia de Loaysa que obligués Huçmen a retre comptes. Com que sembla que els mètodes usats per Garcia de Loaysa eren força expeditius i molestos per a Huçmen, aquest demanà la intervenció de l'arrais de Crevillent a favor seu que, al seu torn, féu que el rei el defensés; però després, com que els infants de Portugal també sol.licitaren la intervenció de Jaume II perquè Huçmen retés comptes, el rei es veié obligat a manar al procurador Pere de Montagut que l'obligués a retre'ls a Garcia de Loaysa. Les reclamacions de l'infant Alfons de Portugal es feren extensives després a altres administradors anteriors, com un tal Açmet, fill de Melic, sarraí d'Elda i altres persones, tant cristians com sarraïns, que s'havien absentat del regne per no retre comptes. L'infant de Portugal exigí, fins i tot al mateix Garcia de Loaysa, que retés comptes, ja que havia rebut

76 ACA, C, reg. 340, f. 157 r. (1296, juny, 20).

77 ACA, C, reg. 104, f. 83 v. (1296, setembre, 8).

78 ACA, C, reg. 254, f. 35 r. (1301, febrer, 24), publ. per J. M. del ESTAL, El reino de Murcia bajo Aragón, 1/2, doc. 196.

79 ACA, C, reg. 128, f. 171 r. (1303, juny, 20).

80 ACA, C, reg. 116 , f. 306 v. i reg. 118 f. 2 r. (1301, gener, 3 i 13).

81 ACA, C, reg. 254, f. 35 r. (1301, febrer, 23), publ. per J. M. del ESTAL, El reino de Murcia bajo Aragón, 1/2, doc. 195. 
les rendes en nom seu i a més havia venut alguns castells seus i a aquest fi envià a la Corona catalano-aragonesa Arias Cabral ${ }^{82}$.

No sembla pas que la persecució a Uçmen Abentaçila perquè retés comptes afectés gaire la seva credibilitat davant de don Juan Manuel, germà de la infanta de Portugal, ja que fou ell la persona escollida per a organitzar la pobla de moros que volia fer a Alarcón ${ }^{83}$.

Segons els càlculs que vam fer a base de l'impost del cabeçatge i de l'impost de gallines, tots dos del 1315, Elda devia comptar amb 1.200 habitants sarraïns, aproximadament, mentre que Novelda en devia tenir entre 850 i $900^{84}$.

Asp. Asp pertanyia en el moment de la conquesta a don Juan Manuel, però la població, habitada gairebé exclusivament per sarraïns, acceptà la senyoria de Jaume II molt abans que don Juan pactés la treva, com Monòver i Xinosa, el 4 de juny de 1296. El govern del lloc fou confiat, de moment, a l'arrais de Crevillent. Després de la sentència arbitral de Torrellas, el lloc passà al patrimoni reial ${ }^{85}$.

Segons els càlculs que vam fer a base de l'impost del cabeçatge i de l'impost de gallines, tots dos del 1315, Asp devia comptar amb uns 650 habitants sarraïns, aproximadament ${ }^{86}$.

\section{Oriola}

Oriola era vila reial. En el moment de la conquesta per Jaume II sembla que devien viure a la vila d'Oriola, en un raval extramurs, prop del pont, un nombre encara considerable de sarraïns. Joan Baptista Vilar va aventurar la xifra de 1.650 habitants sarraïns per a la vila i el terme. A mitjan segle XIV no sembla que fossin més d'uns 200 , si ens basem en l'impost del cabeçatge; a tot el terme devien ser llavors uns 600 , si tenim en compte que hom considerava que, a la Daia, li corresponia de pagar un terç de limpost.

La població sarraïna d'Oriola anà disminuint durant tota la primera meitat del segle XIV i, després de la guerra amb Castella dita dels dos Peres, la moreria d'Oriola desaparegué. Respecte a l'organització interna de l'aljama, me'n vaig ocupar al meu llibre i no repetiré ara les dades exposades allà ${ }^{87}$.

Les petites comunitats de l'horta depenien teòricament de l'aljama d'Oriola, bé que estaven molt condicionades pel senyoriu al qual pertanyien, tal com ho proven les resistències a contribuir en els impostos d'Oriola, com aquesta vila pretenia.

82 ACA, C, reg. 133, f. 76 r. i f. 116 v. (1304, agost, 23 i novembre, 24), reg. 134, f. 136 v. i 234 r.i v. (1304, novembre, 12 i 1305, febrer, 28), reg. 235, f. 153 r. (1304, novembre, 12), reg. 136, f. 204 r. (1305, setembre, 13) i A. GIMÉNEZ SOLER, Don Juan Manuel, doc. CV, pp. 307-308.

83 ACA, C, reg. 203, f. 138 r. i 142 r. (1306, abril, 9 i 10), cf. M.T. FERRER, Les aljames sarraïnes, p.45.

84 M.T. FERRER, Les aljames sarraines, pp. 48 49 i 73.

85 M.T. FERRER I MALLOL, "La conquesta de les comarques meridionals valencianes per Jaume Il», en curs de publicació a Quaderns del Migjorn, i M.T. FERRER, Les aljames sarraïnes, pp. 32-33.

86 M.T. FERRER, Les aljames sarraïnes, pp. 48-49.

87 M.T. FERRER, Les aljames sarraines, pp. 55-59 i doc. 4. 
Entre aquestes aldees de l'horta destacava Almoradí, de població mixta de cristians i sarraïns, bé que dins el terme hi predominaven els sarraïns, especialment a la Daia. Aquest lloc, que pertanyia a Fernando Pérez de Guzmán, fou donat pel rei al seu conseller Guillem Durfort ja el 27 d'abril. El 10 de maig, quan el monarca ja havia adquirit Oriola i el terme es podia considerar segur, demanà als habitants cristians i sarraïns del lloc i de la rodalia d'Almoradí que tornessin a residir-hi, els posà sota el seu guiatge $i$ els manà que obeïssin Guillem Durfort ${ }^{88}$.

L'alqueria de Catral, on també residien un nombre indeterminat de sarraïns, fou donada pel rei al seu fidel servidor Ferran Garcés de Rueda, que havia tingut un paper important en les negociacions amb l'arrais de Crevillent i altres senyors del regne. La primera donació, condicionada per la possibilitat que els propietaris reconeguessin Jaume II com a rei de Múrcia, es produí el 25 de maig, quan el monarca li concedí les possessions dels hereus d'Alemany de Puig i d'Alfonso García de Panpliga, que tenien tots dos part de Catral, a més d'altres propietats a Ceutí, Elx, Múrcia i Villena; la donació definitiva tingué lloc el primer de juliol, quan el mes de temps donat als cavallers i propietaris del regne de Múrcia per a reconèixer Jaume II com a rei havia passat sobradament ${ }^{39}$; posteriorment vengué el lloc a Bernat de Sarrià, a qui Pere de Montagut, procurador del regne, l'embargà entre 1304 i 1305, segurament per procedir a la restitució dels béns confiscats als castellans durant la guerra, restitució pactada a la pau amb Castella ${ }^{90}$; com a senyor de Catral, Ferran Garcés de Rueda s'ocupà de buscar i reclamar els sarraïns d'aquesta alqueria que havien estat capturats durant les operacions bèl.liques, abans del mes de juliol de $1296^{91}$.

Albatera i Coix, de població sarraïna, pertanyien a l'arrais de Crevillent. El 14 de maig, Jaume II concedí guiatge als moros d'aquests llocs, juntament amb els de Crevillent, perquè hi poguessin tornar i poguessin dedicar-se novament a les tasques agrícoles i poc després, el 23 del mateix mes, confirmà a l'arrais la possessió d'aquests llocs ${ }^{92}$.

Redovà també era de senyoriu i de població majoritàriament sarraïna. Havia pertangut al noble castellà Rodrigo Iñíguez $i$ als seus fills, als quals l'alqueria fou confiscada per Jaume II, que la concedí el 1296 a Ramon Sacoma, un veí d'Alacant que havia col-laborat amb les seves tropes en la presa d'Alacant. També devien ser de població sarraïna Xàcara i Xacarella, confiscades a Pero i a Munyo Díaz i donades a Berenguer de Liminyana, d'Oriola, Algorfa, que pertanyia a l'orde de Santiago, Orxell etc. ${ }^{93}$.

88 Ibidem, pp. 6-8 i doc. 2. La donació de la Daia a Guillem Durfort fou publicada per J. M. del ESTAL, Corpus documental del reino de Murcia bajo la soberania de Aragón (1296-1304/5). Colección de Documentos Medievales Alicantinos, 1/1, Alacant, 1985, doc. 7, que publica al doc. 6 el mateix document en la versió del reg. 340.

89 ACA, C, reg. 340, f. 97 v. (1296, maig, 25) i reg. 194, ff. 245 v.-246 r. (1296, juliol, 1).

90 M.T. FERRER, Les aljames sarraines, p. 7.

91 M.T. FERRER I MALLOL, La frontera amb l'Islam, doc. 6.

92 M.T. FERRER I MALLOL, Les aljames sarraïnes, doc. 5 i p. 17.

93 Ibidem, pp. 9-10. 
Favanella, situada al límit entre els termes municipals d'Oriola i Múrcia, era una aldea de població predominantment sarraïna, que fou disputada, acabada la guerra, entre tots dos municipis, que exhibien, l'un i l'altre, privilegis dels reis de Castella atribuint-la al terme respectiu ${ }^{94}$. En nom de Guillem de Rocafull, que era el senyor del lloc, el regia Miquel Garcia, alcaid del castell. Els sarraïns n'estaven queixosos, però ignorem quines eren les ofenses que els havia fet; si més no, pel gener de 1301 es negaven a obeir-lo i a pagar-li les rendes; a més, amenaçaven abandonar el lloc i traslladar-se a viure en uns altres indrets. Jaume II hagué de demanar-los que no marxessin, prometent-los que no se'ls faria cap injúria, però els ordenà que obeïssin l'alcaid i li paguessin les rendes. A l'alcaid, el rei li perdonà tot el que hagués fet malament fins al gener de 1301, però l'advertí que en el futur hauria de respondre del que els fes davant els oficials reials ${ }^{95}$.

Pel que fa als impostos, els sarraîns d'Oriola pagaven també el cabeçatge. Jaume Il el donà al municipi perquè en destinés el producte a les obres de reparació $i$ construcció de les muralles, bé que una tercera part s'havia d'esmerçar en la reparació del castell. Sembla que el rei no féu altra cosa, en realitat, que confirmar el que ja s'havia establert a la vila en temps dels reis de Castella. Com a Alacant, a Oriola també es reivindicà el cabeçatge de les aldees pròximes, com la Daia, que al.legava immunitat, o Catral. L'any 1302, els sarraïns d'aquestes alqueries, que pertanyien llavors a Bernat de Sarrià, s'havien negat a pagar la part que els pertocava en la peita, conjuntament amb els sarraiins d'Oriola. En aquest cas, el rei ordenà que fossin obligats a pagar ${ }^{96}$. Finalment, l'any 1314, Jaume II concedí l'impost al que era llavors el senyor del lloc, Gonçalvo Garcia ${ }^{97}$.

En concepte d'alfarda o peita, els sarraïns d'Oriola pagaren 3.000 sous de reials, l'any $1312^{98}$. Suposo que devia ser la quantitat habitual, al començament del segle XIV, perquè era una quantitat fixa, com la quèstia dels cristians, que es repartia internament a l'aljama segons la riquesa de cadascun. Aquests eren, amb el quirat, els impostos més importants dels que pagaven els sarraïns, però en trobem poques notícies durant els anys de la guerra.

Cal fer esment encara de les prestacions de treball. L'any 1296, el rei els demanà de contribuir amb una persona per cada casa, amb una bèstia, un dia cada setmana,

94 M.T. FERRER I MALLOL, Abanilla y Jumilla en la Corona catalano-aragonesa (s. XIV), a Homenaje al Profesor Juan Torres Fontes, Murcia, Universidad de Murcia-Academia Alfonso X el Sabio, 1987, pp. 484-490. Sobre Favanella cf. també l'estudi més general de J. TORRES FONTES, El señorío de Abanilla, Múrcia, Patronato de Cultura de la Excma. Diputación de Murcia, 1962.

95 ACA, C, reg. 116, ff. 313 v. i 314 r. (1301, gener, 4 i 5).

96 ACA, C, reg. 120, f. 234 r. (1302, gener, 19). Publ. seguint la versió d'un còdex guardat a Oriola per J. M. del ESTAL, El reino de Murcia bajo Aragón, I/1, doc. 183. Publ. també per M. L. CABANES CATALÀ, El còdex d'Elx, Elx, Ajuntament d'Elx i Generalitat de València. Consell Valencià de Cultura, 1995, doc. [IXC], p. 233. Sabem que Bernat de Sarrià posseïa Catral, comprada a Ferran Garcés de Rueda, i la Daia, comprada a Guillem Durfort: M.T. FERRER, Les aljames sarrainnes, pp. 7-8 i Organització i defensa d'un territori fronterer, p. 36, 41 i 48 i ACA, C, reg. 131, ff. 5 v. 6 r. (1304, gener, 6).

97 M.T. FERRER, Les aljames sarraines, pp. 132-133.

98 ACA, C, reg. 326, f. 86 r. 
per a obres que feia a Callosa, que sabem que eren un forn i un camí. Més tard, rectificà aquesta petició per errònia i aclarí que la contribució era d'un dia cada mes ${ }^{99}$.

\section{Múrcia}

Sens dubte, Múrcia i la seva horta acollien encara una comunitat de sarraïns prou notable a la fi del segle XIII, malgrat la pèrdua de població experimentada després de la revolta.

Era presidida per un príncep de la dinastia lbn Hud, que havia estat respectada per Alfons $X$ el Savi, a precs del rei de Granada; aquest príncep era conegut pel títol d'exrei de Múrcia o bé de rei de la Reixaca de Múrcia, el barri on havien estat relegats els moros de la capital.

Segons la crònica d'Alfons el Savi, després de la submissió que acabà la revolta de 1264-1265, Alfons X nomenà rei moro de Múrcia Muhammad ibn Hud i li concedí la tercera part de les rendes del regne de Múrcia; Muhammad passà a viure a la Reixaca, on havia estat concentrada la població musulmana, i se li concedí per a allotjarse el palau Saguir. De les propietats que conservà en un primer moment, en va anar perdent una bona part, inclòs el palau Saguir, al mateix temps que disminuïa la població sarraïna, que continuà emigrant cap a Granada ${ }^{100}$. Poc abans que esclatés la guerra, l'any 1295, Ferran IV havia autoritzat el rei de la Reixaca perquè vengués els seus béns en el regne de Múrcia i Abrahim Aboçac ibn Hud havia usat aquest permís per a vendre el lloc de Fortuna a un veí de Múrcia, Aparici de Nompot, que en realitat comprava en nom del seu gendre Pere Giralt. Jaume II, a petició d'aquest darrer, confirmà la venda el 10 de juny de 1296, quan ja s'havia apoderat d'una bona part del regne ${ }^{101}$.

Després de la capitulació de Múrcia, el 19 de maig de 1296, Jaume II volgué mantenir la preeminència $i$ els privilegis de què havia gaudit la família ibn Hud $i$ una de les primeres coses que va fer fou confirmar, ja el 21 de maig, alguns d'aquests privilegis a favor d'Abutzac ibn Hud, que era el titular llavors de la dinastia hudita. Li donà, concretament, la justícia sobre els sarraïns de Múrcia, la vuitena part de les rendes de l'almoixerifat de Múrcia i el dret del mercat de les bèsties que, segons el privilegi de Jaume II, eren les coses que el rei Alfons de Castella li havia concedit després de perdonar-los l'error de la insurrecció aconsellada pel rei de Granada, en paraules del mateix document. Ignorem si aquestes rendes eren la meitat del total de les de Múrcia que, segons la Crònica d'Alfons $X$, aquest rei donà al rei de la Reixaca, però no sembla pas que ho fossin en aquest moment; de tota manera, eren una bona renda ${ }^{102}$.

99 ACA, C, reg. 104, f. 88 r. (1296, setembre, 10) i reg. 109, f. 284 v. (1297, agost, 30).

100 J. TORRES FONTES, «Los mudéjares murcianos en el siglo XIII», Murgetana, XVII (1961), pp. 7-9 de l'extret.

101 ACA, C, reg. 340, f. 149 v. (1296, juny, 10). Cf. l'autorització del rei Ferran al rei de la Reixaca $i$ altres documents relatius a la venda de Fortuna a J. TORRES FONTES, Fortuna, docs. 2-4.

102 ACA, C, reg. 340, f. 166 v. (1296, maig, 21). Comentat molt breument per P. GUICHARD, Un señor musulmán en la España cristiana, p. 27. 
Sorprenentment, el 22 de juny, en una carta demanant que fossin buscats dos captius negres musulmans, que es creia que s'havien refugiat a la Reixaca, el rei esmentà com a rei dels moros de la Reixaca de Múrcia Mahomet Aboabdilla, que havia estat el primer titular després de la insurrecció; suposem que es tracta d'un error ${ }^{103}$. Un any més tard, quan tornem a trobar mencionat el rei de la Reixaca, és esmentat altra vegada Abutzac, bé que el nom pren la forma més simple d'Açac. Abutzac havia protestat perquè per a collectar les rendes que hem esmentat abans havia comptat sempre amb un escrivà seu que exercia la seva tasca juntament amb l'almoixerif; però llavors Bernat Colomet, que era el batlle general del regne de Múrcia, no permetia l'actuació d'aquest escrivà. Jaume II manà al batlle general que l'autoritzés de la manera acostumada $i$ que respectés els privilegis que li havia atorgat ${ }^{104}$.

També és el mateix Abutzac el personatge a qui el rei reconegué el dret de tenir en servei de la Corona deu cavallers sarraïns amb cavall $i$ armes, estipendiats per l'erari públic. Pel juliol de 1297, Jaume II ordenà al batlle general que li pagués el que li era degut per aquest concepte, ja que només li havien estat pagats 800 sous reials. L'ordre valia tant per al passat com per al futur, és a dir, el batlle li hauria de pagar regularment el salari militar ${ }^{105}$. Suposo que el rei de la Reixaca degué morir per aquest temps, perquè el seu nom desapareix dels documents. Quan, pel maig de 1303, Jaume II envià al batlle general Ferrer Descortell la lista de la gent d'armes que era al seu servei a Múrcia, el rei de la Reixaca ja no hi apareix amb els seus deu cavalls armats, mentre que sí que hi surt l'arrais de Crevillent amb dos cavalls armats i quatre d'alforrats ${ }^{106}$. És possible que la desaparició del rei de la Reixaca sigui anterior al mes d'abril de 1301; crec que és significatiu que en aquest moment l'arrais de Crevillent, Muhammad, fos nomenat jutge dels sarraïns de la Reixaca ${ }^{107}$, atès que, com sabem, la justícia sobre els moros era un dels privilegis de què gaudia Abutzac. Cal no oblidar que la família dels ibn Hudayr estava emparentada amb els ibn Hud. Una filla de Muhammad ibn Hud, Abnatalaziz, era la muller de l'anterior arrais, Ahmad, que era el personatge més notable entre els moros del regne; un home, a més de la plena confiança de Jaume II.

Segurament era un germà d'Abutzac l'arrais Abonega o Abenayça. Immediatament després de l'ocupació de Múrcia, pel maig de 1296, el rei li confirmà la possessió d'un forn que tenia a la Reixaca i de sis faneques de terra prop de Múrcia ${ }^{108}$, i l'any 1301 li atorgà franquícia d'impostos per aquest mateix forn en consideració als serveis que li havia prestat amb un cavall alforrat ${ }^{109}$,

Pel que fa als sarraïns de la Reixaca, no hi ha gaires documents que els afectin en

103 ACA, C, reg. 340, f. 165 r. (1296, juny, 22).

104 ACA, C, reg. 253, f. 45 v. (1297, juliol, 3).

105 ACA, C, reg. 253, f. 45 v. (1297, juliol, 3).

106 M.T. FERRER, Organització i defensa, doc. 32.

107 ACA, C, reg. 198, f. 281 v. (1301, abril, 18); vegeu més amunt quan parlo de l'arrais de Crevillent.

108 ACA, C, reg. 340, ff. 107 v.-108 r. (1296, maig, 24), publ. per J. M. del ESTAL, El reino de Murcia bajo Aragón, 1/1, doc. 92.

109 ACA, C, reg. 198, f. 255 r. (1301, febrer, 15). 
els primers temps; probablement tot passava a través de l'exrei de Múrcia. No trobem cap guiatge als sarraïns de la Reixaca fins a la confirmació dels privilegis de Múrcia, que inclogué un assegurament als sarraïns $i$ jueus que prestessin obediència a Jaume II ${ }^{110}$. Poc després, el 20 d'agost, el rei els afavorí amb una rebaixa de 800 sous reials del cabeçatge de les vídues sarraïnes, del cabeçatge dels sarraïns i d'altres peites, durant un període de deu anys; amb aquesta concessió els volia compensar pels danys rebuts en temps passat ${ }^{111}$. El mateix mes ordenà al seu germà Jaume Pere, procurador del regne de Múrcia, que defensés els moros de la Reixaca contra els que els volguessin injuriar o molestar, sempre que estiguessin disposats a fer dret als querellants contra ells ${ }^{112}$.

Una nova intervenció del rei a favor dels sarraïns de la Reixaca es produí el setembre del mateix any, perquè s'havien queixat que el batlle de la ciutat de Múrcia els impedia de fer talles entre ells per a recollir els diners necessaris per a afrontar algunes despeses que havien de fer. La resposta del rei fou també la de fer respectar els costums dels sarraïns ${ }^{113}$.

Bernat Colomet obtingué una clarificació de les seves funcions respecte als sarraïns pel setembre de 1296. El rei declarà que ningú més que ell no podia intervenir en les qüestions que afectessin jueus i sarraïns del regne de Múrcia; els altres oficials havien d'abstenir-se d'intervenir-hi' ${ }^{144}$. Però no pas sempre el batlle obtingué l'aprovació reial en la seva gestió de les qüestions sarraïnes. Pel juliol de 1297, el rei desaprovà l'organització d'una tarcana o bordell per a meretrius sarraïnes a la Reixaca i ordenà tancar-la i expulsar-ne les dones ${ }^{115}$.

Durant els anys següents, les notícies que tenim dels moros de la Reixaca, com a col-lectiu, són pràcticament inexistents, llevat d'algunes de referents a convocatòries a l'exèrcit que ja he comentat.

Noves queixes arribaren, per l'abril de 1303, ara dins l'esfera de poder del batlle general, Ferrer Descortell. Els sarraïns es queixaven perquè el sabasala, el mostassà i l'alcadí eren obligats a pagar el cabeçatge, quan n'eren exempts; el rei els donà la raó i manà que no els fos exigit; una altra queixa era que per Pasqua pagaven per cap un almud de gra del que compressin per a menjar aquell dia; però els colllectors els demanaven no pas un almud del gra que compraven aquell dia, que suposem que intel.ligentment devien procurar que fos un gra de baixa qualitat, sinó que el demanaven gairebé tot de blat; d'aquesta queixa, el rei volgué rebre'n més informació abans de decidir. També el mateix dia el rei manà que fos respectat el privilegi que tenien de ser empresonats a la presó dels sarraïns ${ }^{16} \mathrm{i}$, per tal de repoblar la Reixaca, concedí que

110 ACA, C, reg. 194, f. 226 r.-v. (1296, agost, 3).

111 ACA, C, reg. 194, f. 242 r. (1296, agost, 20). Cit per P. GUICHARD, Un señor musulmán en la España cristiana, p. 27.

112 ACA, C, reg. 104, f. 45 r. (1296, agost, 21).

113 ACA, C, reg. 104, f. 101 r. (1296, setembre, 21).

114 ACA, C, reg. 104, f. 107 v. (1296, setembre, 22).

115 ACA, C, reg. 253, f. 45 v. (1297, juliol, 3).

116 ACA, C, reg. 127, f. 109 v. (1303, abril, 25). 
els sarraïns forasters que s'hi instal-lessin per a residir-hi, almenys un any, gaudissin d'exempció de cabeçatge $i$ alfarda durant aquest any ${ }^{117}$. Pocs dies després el rei confirmà l'arrais de Crevillent com a jutge dels sarraïns de la Reixaca de Múrcia i altres llocs del regne ${ }^{118}$. Suposo que aquesta acumulació de decisions favorables als moros de la Reixaca degué correspondre a l'arribada d'algun missatger de l'aljama amb un memorial de queixes i peticions a la cort, a València, o potser fou el mateix arrais qui exercí la seva influència prop del rei a favor dels moros de Múrcia. En qualsevol cas, les queixes són molt interessants per a completar la nostra informació sobre alguns impostos, com el de l'almud de gra per cap, que podria ésser l'alfatrà 119.

Cal dir que també he trobat algunes notícies sobre l'alfòndec de Múrcia, on s'hostatjaven els sarraïns forasters, que fou concedit, juntament amb l'escrivania de la duana o pes, a Arnau d'Esparraguera ${ }^{120}$. Més endavant, sabem que les rendes de l'alfòndec, juntament amb altres, serviren per a garantir una pensió de 1000 sous barcelonins anuals que havia de rebre Berenguer de Miramon, ciutadà de Múrcia; aquestes altres rendes que servien de garantia eren l'almoixerifat $i$ un dret anomenat la "partaça", que pagaven els sarraïns estrangers pels animals carregats de mercaderia quan sortien de la ciutat de Múrcia ${ }^{121}$. També tenim constància de la concessió de l'escrivania dels sarraïns de Múrcia a Joan Pere de Maylén, un home de la casa del $\mathrm{rei}^{122}$.

Personatges notables que trobem esmentats són per exemple Mahomet Alhale, mestre alarif dels sarraïns de Múrcia, a qui fou concedida franquícia de peita el 1298. Un altre mestre, de qui no podem llegir el nom, rebé un donatiu de 55 sous reials de Múrcia sobre la peita ${ }^{123}$. També tenim notícia d'un mercader de Múrcia que havia anat al Marroc sense llicència, una terra amb la qual no hi havia pau, bé que tampoc en aquell moment no hi havia hostilitats obertes, i que quan en tornà fou empresonat, per aquesta raó, a València. El mercader en qüestió, del qual no sabem el nom, es beneficià del fet que els mercaders de Barcelona, de València i d'altres llocs dels regnes de Jaume II s'interessaren perquè fos alliberat, ja que temien que Abenjacob no exercís alguna represàlia contra els mercaders catalans i valencians que eren en aquell moment al Marroc ${ }^{124}$.

117 ACA, C, reg. 200, f. 214 v. (1303, abril, 25), publ. per J. M. del ESTAL, El reino de Murcia, doc. 188.

118 ACA, C, reg. 127, f. 114 r. (1303, abril, 28).

119 A la part septentrional de l'antic regne de Múrcia aquest impost es consolidà amb la petició d'un almud d'ordi per cap: M.T. FERRER, Les aljames sarraïnes, pp. 46-48 i 133; J. HINOJOSA MONTALVO, "Crevillente: una comunidad mudéjar en la Gobernación de Orihuela en el siglo XV", a IV Simposio Internacional de mudejarismo: Economía, pp. 310-312

120 ACA, C, reg. 340, f. 147 v. (1296, juny, 16).

121 ACA, C, reg. 256, f. 40 r.-v. (1298, febrer, 8).

122 ACA, C, reg. 196, f. 191 v. (1298, febrer, 23).

123 ACA, C, reg. 196, ff. 129 v.-130 r. i v. (1298, febrer, 7).

124 ACA, C, reg. 128, f. 215 r. (1303, juliol, 18). 
Les comunitats sarraïnes de l'horta de Múrcia varen patir força la guerra. Ja m'he referit al començament als captius que foren presos a Albudeite. El 13 de juny, el rei posà sota el seu guiatge tant els moros de Pliego com els d'Albudeite, però no els serví de gaire perquè pocs dies després sofriren una cavalcada dels homes de Lorca, que lluitaven encara pel rei de Castella ${ }^{125}$.

Una altra cavalcada de l'adalil Vicenç de Xixona per Ceutí i Lorquí durant el mes de maig de 1296 aconseguí també, com ja hem dit més amunt, diversos captius sarraïns, el nombre dels quals no és especificat. El rei consentí la venda dels de Ceutí i Lorquí, però no d'alguns moros d'Alguazas que també havien estat presos, en part perquè el lloc pertanyia a la seva tia, la reina Violant, i en part perquè l'havia concedit al seu conseller Ramon de Manresa ${ }^{126}$. El 13 de maig, un sarraí d'Alguazas de Molina, anomenat Açmet Acurubi, obtingué un guiatge particular per a anar i venir a Múrcia 0 a Alguazas, amb bestiar $i$ altres coses ${ }^{127}$, i el 19 tots els sarraïns del lloc obtingueren guiatge per a les seves terres i per a les persones i per a circular i residir en qualsevol lloc que volguessin del regne de Múrcia ${ }^{128}$. Un mes després el rei encara s'ocupà novament dels sarraïns de les Alguazas, ara perquè s'havien queixat que hom no els deixava usar l'aigua, com acostumaven en temps passat, i que per aquesta causa els seus conreus resultaven perjudicats; el rei manà al batlle de Múrcia que els deixés usar l'aigua segons el costum ${ }^{129}$.

Els sarraïns de les Alguazas foren afortunats perquè el projecte reial de fundar un monestir al Real de Múrcia dependent de Santes Creus féu que el monarca afavorís els llocs que donava al monestir, entre els quals figurava les Alguazas. Així, doncs, per l'octubre de 1297 manà al procurador que els sarraïns del monestir no fossin obligats a contribuir pels béns que tenien a l'almoixerif de la Reixaca de Múrcia i, quan pel desembre d'aquell any els sarraïns hagueren de refugiar-se a Múrcia per viure segurs, ja que els castellans feien cavalcades pel territori, també els defensà contra la pretensió del batlle i de l'almoixerif de fer-los pagar el cabeçatge, com si hi visquessin de manera permanent ${ }^{130}$. Però el 1298 calgué una nova intervenció del rei perquè Santes Creus

125 ACA, C, reg. 340, ff. 149 r. (1296, juny, 13)i 168 r. (1296, juny, 24). La vila de Pliego ja havia rebut abans un altre guiatge, el 20 de maig, però no esmentava els moros: ibídem, $f$. 77 r.

126 ACA, C, reg. 340, f. 71 r. i 73 r.-v (1296, maig, 17 i 18), aquest darrer publ. per. J.M. del ESTAL, El Reino de Murcia bajo Aragón (1296-1305). Corpus documental, 1/1, doc. 64 i 1/2, doc. 39. Cf. la concessió a Ramon de Manresa a ibídem, doc. 29. Sobre el senyoriu de la reina Violant sobre Alguazas cf J. TORRES FONTES, «El señorío de Alguazas en la Edad Media», Murgetana, XLIX (1977), pp. $81-114$ i concretament pp. 85-90.

127 ACA, C, reg. 340, f. 75 r. (1296, maig, 13).

128 ACA, C, reg. 340, f. 75 r. (1296, maig, 19), publ. per J. M. del ESTAL, El reino de Murcia bajo Aragón, $1 / 1$, doc. 75 .

129 ACA, C, reg. 340, f. 177 r. (1296, juny, 27).

130 ACA, C, reg. 106, ff. 91 r.-v. (1297, octubre, 30), i 135 r. (1297, desembre, 10), cit. R. SÁINZ DE LA MAZA LASOLI, «EI monasterio cisterciense del real de Murcia. Un proyecto fracasado de Jaime Il», Anales de la Universidad de Alicante. Historia Medieval, 9 (1992-93), p. 184. 
s'havia queixat de l'actuació de mestre Bernat, l'almoixerif de la Reixaca de Múrcia, que havia pres al monestir els impostos d'alfatrà i cabeçatge que tenia sobre els sarraïns de les Alguazas i el quirat que tenia sobre els sarraïns de Monteagudo ${ }^{131}$. Els sarraïns que habitaven a les Alguazas, però a la part que pertanyia a Ramon de Manresa, també obtingueren alguns favors, com el de no haver d'acudir a l'exèrcit i no haver de deixar les seves bèsties ${ }^{132}$.

\section{Cartagena}

Tenim molt poques notícies dels moros que vivien a Cartagena. El 3 de juny de 1296 Jaume II concedí un guiatge conjunt a tots els veïns de Cartagena, tant als cristians, com als sarraïns i als jueus, i franquícia i llibertat de moviments per a persones i mercaderies per tot el regne. El guiatge comportava al mateix temps la suspensió de totes les accions judicials pendents per actes i crims comesos amb anterioritat sota règim castellà. Un mes després, Jaume II confirmà al municipi de Cartagena i a tots els veïns, cristians, sarraïns i jueus, els furs i les franquícies concedits pels reis de Castella ${ }^{133}$.

Sabem que, a la primeria de juliol de 1296, alguns prohoms de Cartagena havien intercedit prop del rei, que es trobava al setge d'Elx, perquè perdonés als sarraïns de Cartagena alguns impostos que el seu representant a la vila els exigia. Els prohoms asseguraven que els moros es trobaven en una gran misèria i que no podien pagar $i$, per això, el rei ordenà de sobreseure l'exacció fins que ell no tornés a Múrcia i decidís sobre el cas ${ }^{134}$.

És tot el que en sabem.

\section{Mula}

Tampoc no és gaire més el que sabem dels moros de Mula, que ensimaginem que devien ser pocs. El privilegi de confirmació per part de Jaume II dels privilegis, donacions, bons usos i costums, que els reis de Castella havien concedit als veïns de Mula, esmenta els sarraïns al costat dels cristians $i$ jueus ${ }^{135}$. Sembla que en altre temps Mula havia tingut una moreria important, però durant els anys dels quals ens ocupem a penes si és esmentada; acabada la guerra, Mula sol.licità de repoblar la seva moreria amb seixanta casats d'altra procedència ${ }^{136}$.

131 ACA, C, reg. 110, f. 53 r. (1298, març, 31).

132 ACA, C, reg. 111, f. 215 v. (1298, maig, 19).

133 ACA, C, reg. 340, ff. 240 v. -241 r. i 283 v.-284 r. (1296, juny, 3 i juiol, 15), publ. per J.M. del ESTAL, El reino de Murcia bajo Aragón, l/1, docs. 97 i 117.

134 ACA, C, reg. 340 , f. 214 r. (1296, juliol, 10).

135 ACA, C, reg. 340, f. 280 v. (1296, agost, 2), publ. per J. M. del ESTAL, El reino de Murcia, I/ 1, doc. 126.

136 J. TORRES FONTES, Los mudéjares murcianos en el siglo XIII, pp. 26-27. 
Durant la guerra, únicament hi ha constància de mesures preses contra un jueu de Mula, Abulfacem, que vivia en concubinatge amb una sarraïna, anomenada Axona. El procurador de Jaume II, el seu germà Jaume Pere, els havia empresonats, però el rei manà que fossin deslliurats perquè, no essent cristians, opinava que no s'havia d'intervenir en l'afer i l'any següent repetí el manament a Jaume de Xèrica, que succeí en el càrrec el seu germà ${ }^{137}$.

\section{Els llocs dels ordes militars}

Als llocs dels ordes militars, especialment els de l'orde de Santiago, era on segurament, fora de la capital, es concentrava un nombre major de sarraïns, juntament amb Alguazas, Ceutí i Lorquí. Les negociacions amb l'orde de Santiago per al reconeixement de Jaume II s'allargaren un quant temps, però mentrestant els frares de l'orde i els seus moros reberen un guiatge del rei. Un primer guiatge fou expedit el 25 de maig per als llocs de Ricote, Cieza, Aledo i Ojós, durant el termini de trenta dies que el rei donava als naturals del regne per a decidir si el reconeixien com a rei 0 no ${ }^{138}$. L'11 de juny Ferran Pérez, comanador de Ricote, i Joan Martínez, comanador de Cieza, juraren tenir pel rei Cieza, Aledo, Negra i Ojós i Ricote ${ }^{139}$. El dia abans, quan el reconeixement ja era imminent, Jaume Il confirmà als llocs de l'orde els furs, privilegis, franquícies, llibertats, donacions i costums concedits pel rei Alfons i pels seus successors a l'orde a Múrcia, amb les mateixes obligacions de serveis en pau i en guerra pels castells que tenia al regne; el dia 12 el rei concedí un nou guiatge als frares de l'orde $\mathrm{i}$ als seus moros al regne de Múrcia i, el 26 del mateix mes, comunicà a les places granadines frontereres de Vélez el Blanco i Vélez el Rubio que els llocs de l'orde de Santiago l'havien reconegut com a rei i, per tant, demanà que no fossin atacats ${ }^{140}$. Els qui, en canvi, no observaren la pau amb Granada foren els súbdits de l'orde, que lluitaren contra genets de Granada que havien fet una cavalcada contra Castella i que, tornant, havien passat per Cieza, on algun fou mort i altres foren retinguts ${ }^{141}$. Problemes semblants es repetiren l'any 1300 a Aledo, amb moros almogàvers de Vélez Blanco, a Totana, on homes d'Aledo degollaren dos granadins, $\mathrm{i}$ a Hellín, on foren retinguts dos granadins més ${ }^{142}$.

A la darreria de desembre de l'any 1300 , sembla que havia corregut entre els moros de la vall de Ricote el rumor que Jaume II i la seva gent estarien contra ells; segons el comanador Ferran Pérez, ell els havia convençut que no es moguessin, quan presumiblement pensaven de fugir cap algun altre lloc més segur, ja que eren sota el guiatge reial. El rei es felicità que fos així en carta al comanador i tornà a confirmar

137 ACA, C, reg. 110, f. 34 v. (1297, març, 26) i 115 v. (1298, abril, 13).

138 ACA, C, reg. 340, f. 93 v. (1296, maig, 25). Cf. més informació sobre tot el que es refereix a l'orde de Santiago a R. SÁINZ DE LA MAZA LASOLI, La orden de Santiago en aquest mateix volum.

139 ACA, C, cr Jaume II, caixa 152, núm. 834.

140 ACA, C, reg. 340, ff. 127 v. i 128 r. (1296, juny, 10 i 12) i f. 177 r. (1296, juny, 26).

141 ACA, C, reg. 107, f. 219 r. (1298, febrer, 11).

142 ACA, C, cr Jaume II, caixa 122, núm. 1423. 
que els moros no havien de témer res. Probablement, els rumors venien del descontentament dels oficials reials envers el comanador, que no solament no col-laborava en la guerra quan se li demanava sinó que ajudava els enemics. El rei li recordà el jurament i l'homenatge que havia prestat i estigué disposat a parlar amb ell d'una possible retirada del regne, donant-li un termini per a tornar els castells al mestre de l'orde, tal com el comanador de Ricote mateix li havia proposat ${ }^{143}$.

Malgrat el canvi de comanador, que efectivament es portà a terme, la inquietud entre els moros de la vall de Ricote no desaparegué. Per tal de resoldre el conflicte, el procurador del regne, Bernat de Sarrià, s'entrevistà a Múrcia amb l'arrais de Crevillent i amb l'ambaixador de Granada, Çahat Acaybilli, i s'hi acordà que els moros de la vall lliuressin quaranta rehenes que servirien de garantia que no acollirien ni ajudarien de dit ni de fet el rei de Castella i la seva gent, ans el contrari, que li farien guerra. Si no complien la seva paraula, les rehenes quedaven per al rei ${ }^{144}$.

Durant l'any 1303 tornem a tenir notícies de la vall de Ricote i de les altres possessions de l'orde de Santiago. Sabem, per exemple, que el rei tornà a posar sota el seu guiatge la vall, Ojós, Negra i Cieza; la repetició dels guiatges fa sospitar que hi havia hagut, novament, tensions a la vall; altrament, el guiatge no hauria estat necessari i, potser per tal de no provocar-ne més, el rei recomanà al batlle general, Ferrer Descortell, que no exigís l'impost de cenes als llocs de l'orde de Santiago si no les pagaven en temps dels reis de Castella ${ }^{145}$.

Pel que fa a les possessions dels Hospitalers, sabem que el castell d'Archena es mantenia rebel a Jaume II l'any 1301, però que els sarraïns que vivien al terme sí que havien acceptat la seva sobirania i s'havien refugiat a Molina Seca; per aquesta causa el rei manà a Bernat de Sarrià que els restituís el blat $i$ altres fruits que havia pres en el transcurs d'una cavalcada a les heretats del terme que pertanyien als dits sarraïns, perquè no eren rebels ${ }^{146}$.

\section{LA PARTICIÓ DEL REGNE}

Després de la pau amb Castella, el 8 d'agost de 1304, només la meitat aproximadament del regne quedà en poder de la Corona catalano-aragonesa, però tenim la impressió que era en aquest territori on hi havia els nuclis més importants de sarraïns, a les comarques d'Elx i de Crevillent, de la vall d'Elda i de Novelda i a les hortes d'Oriola i Alacant i a les seves moreries urbanes.

143 ACA, C, reg. 293, f. 29 r. (1300, desembre, 28), publ. per J. M. del ESTAL, "Nuevos datos sobre la capitulación y conquista aragonesa de Lorca", a Homenaje al profesor J. Torres Fontes, Múrcia, Universidad de Murcia-Academia Alfonso X el Sabio, 1987, I, doc. 14, p. 458 i a El reino de Murcia bajo Aragón, 1/2, doc. 144, cal tenir present, però, que la regesta conté errors respecte al contingut del document.

144 ACA, C, cr, caixa 6, núm. 1110, cf. P. GUICHARD, Un señor musulmán, p. 28 i doc. 4, pp. 7374, publ. també per J. M. del ESTAL, El reino de Murcia, doc. 174.

145 ACA, C, reg. 128, f. 143 v. (1303, maig, 26).

146 ACA, C, reg. 121, f. 10 r. (1301, juny). 
Justament a la fi d'agost de 1304, quan anaven a començar els treballs per a la divisió del regne, es produí una incursió granadina per terra i per mar. Per terra, l'exèrcit nassarita arribà fins a Alcoi i a Cocentaina, que foren assetjades perquè Alabbàs Ben Rahú - el mercenari marroquí que havia estat al servei de Jaume II fins pocs mesos abans - participava en l'expedició i sabia prou bé que no eren llocs gaire forts. Per mar, la flota de Granada s'adreçà a Xàbia, a fi d'unir les seves forces amb les de l'exèrcit de terra. Si aquesta conjunció s'hagués portat a terme i la població sarraïna que habitava a les comarques del sud del País Valencià s'hagués revoltat, com esperaven els invasors, la situació hauria resultat molt compromesa per a Jaume II. Però la flota nassarita, a causa d'un temporal, arribà tard a la cita amb l'exèrcit i no el trobà perquè les tropes de terra ja s'havien retirat; la sublevació dels sarraïns autòctons tampoc no fou generalitzada, però alguns - no sabem quants- participaren en els setges de Cocentaina i d'Alcoi i molts més seguiren l'exèrcit nassarita en la retirada: alguns milers de sarraïns del sud del País Valencià i de la vall del Vinalopó i hortes d'Alacant i Oriola ${ }^{147}$.

No tenim constància que el territori murcià actual també hagués resultat afectat per aquest fenomen migratori, però és força probable. Moltes de les notícies sobre aquesta fugida en massa són de l'any 1305, quan la part meridional del regne de Múrcia ja era fora del control de Jaume II, per això la documentació de la cancelleria reial no ens n'informa; però la carta de Ferran IV de Castella, que hem comentat al començament, potser es refereix a aquest fenomen quan esmenta la despoblació causada per la guerra i per la fugida de molts sarraïns ${ }^{148}$.

L'entrada inesperada de l'exèrcit granadí, en un moment en què es creia que hi havia treva, i els incendis, el pillatge i les fugues de tants sarraïns van causar desconcert entre els cristians; però entre els sarraïns va causar potser més desconcert encara la notícia de la pau amb Castella i de la divisió del regne. Els camperols sarraïns eren gent espantadissa; sempre temien efectes dolents per a ells de qualsevol canvi. L'exemple més significatiu el tenim a Elda i a Novelda, on la notícia produí pànic entre els sarraïns, que abandonaren tots dos llocs per a refugiar-se no sabem on. En aquest cas en concret potser temien que retornarien al poder del rei de Castella i que serien castigats per haver obeït Jaume II. Per això, pel novembre de 1304, el rei els notificà que quedaven sota la seva senyoria, els assegurà i els manà que tornessin a llaurar les seves terres, ja que ell els defensaria ${ }^{149}$.

Resumint, doncs, el final d'una guerra, que havia portat tants patiments, no fou tampoc una bona notícia per a molts sarraïns, que temien un altre canvi de senyor; trigaren un cert temps a asserenar-se.

147 M.T. FERRER, La frontera amb l'Islam en el segle XIV, pp. 79-90.

148 Cf. la nota 9.

149 M.T. FERRER, Les aljames sarraines, p. 73 i doc. 28. 